\title{
A Study on the Determination of Household Portfolio Selection in China—Based on the Empirical Study on Households in the
}

\author{
East \\ Junmin Zhang $^{1^{*}}$ \\ ${ }^{1}$ International School, Jinan University, Guangzhou, China \\ *Junmin Zhang, E-mail: 3035893578@qq.com \\ Received: January 26, 2017 Accepted: February 10, 2017 Online Published: February 16, 2017 \\ doi:10.22158/rem.v2n1p64 URL: http://dx.doi.org/10.22158/rem.v2n1p64
}

\begin{abstract}
Household exerts remarkable influence on the market-oriented economy. Regarding to the importance of household in financial market, the study on the determination of household investors' portfolio selection has attracted tremendous attention of academic circle in recent decades. China Household Finance Survey (CHFS) has been established to conduct household finance research and it suggests that household investors' asset allocation has been diversified in the recent decade with the prosperity of financial market and the booming household income. The study here aims to find out which determinations exerting effects on financial asset selection of Chinese household and the paths of the mechanism.

The paper will conduct both theoretical analysis and statistical analysis. With the help of Stata 12 and Eview 7.2 metrology software, the paper analyzes the influential factors of household financial asset selection and the interactional relationship among the hypothesized variables. Based on the empirical results and conclusions, the study can provide practical suggestion to household investor, asset manager and government.
\end{abstract}

\section{Keywords}

household, portfolio selection, Eastern China, probit, tobit

\section{Introduction}

Thanks to the policy of reform and opening-up, the aggregate wealth of Chinese household is booming with the prosperity of domestic economy. According to the Global Wealth Report 2015 published by Credit Suisse, the aggregate wealth of Chinese family has amounted to 22800 billion dollars. The figure has increased by 1500 billion dollars compared with the year of 2014, and the wealth level of Chinese household ranks second only to that of American family in 2015. Chinese family not only has large 
amount of wealth with the perspective of current situation, but also enjoys the great potential to enlarge the stock of their wealth in the future. The Credit Suisse made prediction in 2013 that the wealth of Chinese family could increase by $62 \%$ in 2018 with the amount of 35900 billion dollars, which weighs $10.8 \%$ of global wealth.

Due to the ascending wealth, Chinese household change their family asset structure to maximize their welfare and satisfy various investment subjective. In the past 20 years, Chinese household held banking deposits as main financial asset. Nowadays, however, they begin to diversify their financial asset, investing in stocks, mutual market money fund, bonds, real estate, future, precious metal and bank financial products. China Household Finance Survey (CHFS) finds that $60.91 \%$ family hold banking deposits, $8.84 \%$ of them invest in stocks, $0.77 \%$ of them choose bonds, $4.24 \%$ of them make investment in mutual funds, while $0.05 \%$ of them hold derivatives and $1.10 \%$ of them invest in bank financial products. In the context of prosperity in household financial market within China, some questions associated with financial asset management have arisen. Which financial asset is the most popular one? Why Chinese household show strong preference to specified asset instead of others? The thesis will resolve these questions by empirical study.

\section{Literature Review}

The foreign research on household portfolio selection has been systemized thanks to the innovation of household financial theory and the empirical study. Cocco et al. (2005) study the issue of optimal consumption level, asset allocation and age when the household plans for their asset. They build up power utility function in the context of life cycle and suggest that the investment demand increases in the early stage of the life cycle, but because of the uncertainty of labor income, the demand is in downward trend when it comes to the aggregate stage. Munk and Sorensen (2010) build up a dynamic model including random interest rate and they declare that the labor income is a critical element which affects the asset allocation among stock, bond and cash.

From the perspective of study on Chinese household financial asset holding, the early study focuses on the household deposits. Later, with the development of behavioral finance and household finance, numerous researchers show interests in exploring the determination of household portfolio selection by applying different models, like tobit model, probit model, logistic model and structural equation modeling. Li (2006) utilizes the data to operate an empirical study of social interaction and financial asset selection. He deems that positive social interaction promotes the individual's current and expected participation in investment project. Wei et al. (2012) use the same data but the econometric model is replaced by structural equation model with additional independent variables. They declare that substitute effect, life cycle effect, wealth effect and the crowding effect of housing procession exert certain effect on the household financial asset construction. Yin et al. (2014) explore that financial knowledge and investment experience are factors affecting the degree of participation in financial market and asset selection. Huang (2014) apply tobit model and probit model to understand the 
relationship among social network, credit constraint and household's portfolio choice, and she concludes that the social network enhances the activeness of participation in stock market and the proportion of fund set aside for share-holding along with the promotion of financial market.

\section{Empirical Study Based on the Sample of Eastern Household}

\subsection{Overview on Chinese Household's Financial Asset Selection}

The following Tables exploit several traits of Chinese household's financial asset holdings:

First of all, risk-free asset was major financial asset in Chinese portfolio but its importance has been weakened. The ratio of risk-free assets to total financial asset was $75.68 \%$ in 2013 but it went down to $65.3 \%$ in 2015. Risk-free asset plays an important role in current household's portfolio complying with a weight excessing $50 \%$. On the other hand, its weight has been declining actually in recent five years. Next, there was booming in value of financial asset in the span of 2013 and 2015. As the Tables show that the value of financial asset per capita ascended from 73,000 Chinese Yuan to 122,200 Chinese Yuan from 2013 to 2015 respectively, increasing by $67.40 \%$. What is more noticeable is that the risk-free asset as share of financial asset climbed from 52,300 Yuan to 79,800 Yuan with an increment of $53.1 \%$ during the time from 2013 to 2015 . The increment came from the great ascending of demand deposit and stable rising of time deposit. In brief, increasing value in deposits contributed to the increment in financial asset from 2013 to 2015.

Furthermore, there was sharp rise in risky-assets from the perceptive of median value and procession rate. Even though the Internet financial assets have been popular financial product for Chinese household, the prevalence did not shock to traditional bank product. The evidence is shown by the increasing fund invested in stock and fund from 2013 to 2015. The average value of stock was only 6,000 Yuan in 2013 but it grew to be 13,000 Yuan in 2015. Thanks to the bull market from second half of 2014 to first half of 2015, the investment in stock and fund grew stably during this time horizon.

From the perspective of financial products, the investment in this risky financial assets have been less popular in the last three years. Such change was obvious in the other financial assets investment, in particular, even though household investors increased its fund value. In this side, the emerging Internet financial products offset partial decline in financial product holding. As the Internet financial market is expanding in Chinese financial market, bringing more and more innovative and stylized financial products to household investors. The attractiveness of Internet financial products can be found in the soaring Internet insurance market. From 2011 to 2013, the size of electronic insurance premium increased from 3.2 billion Yuan to 29.1 billion Yuan with the promotion of $8.10 \%$ in three years. The population of electronic insured went from 8.16 million to 54.37 million within Chinese market. The rapid growth of Internet insurance shocked to traditional insurance companies and the emerging Internet insurance did erode the traditional insurance market. Thus, it is possible that emerging Internet financial products will take the placement of traditional financial products which are mainly provided by traditional financial institutions. Traditional financial intermediaries should renew their financial 
products to fight against the potential new-comer otherwise their market share will be encroached soon. When it comes to loan lent, its change was not so fluctuated. But based on the figures shown in the following Tables, loan lent which the fund is lent from host household to the other households was held by Chinese household more or less in these three years. Besides, it was a common risky asset in Chinese portfolio.

Last but not least, the Tables illustrated that the procession rate of financial assets was pretty high in China which was over $96 \%$ along with the larger amount of fund put in financial assets. This finding is consistent with the conclusion drawn by previous researchers that household become more important in Chinese financial market being a critical market participators in domestic financial marketplace.

Table 1. Financial Assets Structure of Chinese Household from 2013 to 2015

\begin{tabular}{llllll}
\hline & \multicolumn{4}{l}{ Mean (thousand Yuan) } & \multicolumn{2}{l}{ As share of financial assets (\%) } \\
\cline { 2 - 6 } & $\mathbf{2 0 1 3}$ & $\mathbf{2 0 1 5}$ & Change & $\mathbf{2 0 1 3}$ & $\mathbf{2 0 1 5}$ \\
\hline Financial assets & 73 & 122.2 & $67.40 \%$ & $100.00 \%$ & $100.00 \%$ \\
Risk-free assets & 52.3 & 79.8 & $52.58 \%$ & $71.64 \%$ & $65.30 \%$ \\
Cash & 5.4 & 5.8 & $7.41 \%$ & $7.40 \%$ & $4.75 \%$ \\
Demand deposits & 17.7 & 33.2 & $87.57 \%$ & $24.25 \%$ & $27.17 \%$ \\
Time deposits & 14.6 & 19.8 & $35.62 \%$ & $20.00 \%$ & $16.20 \%$ \\
Balance & 14.6 & 20.9 & $43.15 \%$ & $20.00 \%$ & $17.10 \%$ \\
Risky assets & 20.7 & 42.4 & $104.83 \%$ & $28.36 \%$ & $34.70 \%$ \\
Financial products & 3.2 & 10 & $212.50 \%$ & $4.38 \%$ & $8.18 \%$ \\
Bank financial product & 3 & 8.3 & $176.67 \%$ & $4.11 \%$ & $6.79 \%$ \\
Other financial product & 0.2 & 0.6 & $200.00 \%$ & $0.27 \%$ & $0.49 \%$ \\
Internet financial product & $\mathrm{NA}$ & 1 & $\mathrm{NA}$ & $\mathrm{NA}$ & $0.82 \%$ \\
Stocks & 6 & 13 & $116.67 \%$ & $8.22 \%$ & $10.64 \%$ \\
Funds & 1.7 & 3.2 & $88.24 \%$ & $2.33 \%$ & $2.62 \%$ \\
Other risky assets & 2.3 & 1.7 & $-26.09 \%$ & $3.15 \%$ & $1.39 \%$ \\
Loan lent & 7.4 & 8.6 & $16.22 \%$ & $10.14 \%$ & $7.04 \%$ \\
Account receivable & $\mathrm{NA}$ & 5.8 & $\mathrm{NA}$ & $\mathrm{NA}$ & $4.75 \%$ \\
\hline & & & & & \\
\hline
\end{tabular}


Table 2. Financial Assets Structure of Chinese Household from 2013 to 2015

\begin{tabular}{|c|c|c|c|c|c|}
\hline & \multicolumn{3}{|c|}{ Median (thousand Yuan) } & \multicolumn{2}{|c|}{ Procession rate (\%) } \\
\hline & 2013 & 2015 & Change & 2013 & 2015 \\
\hline Financial assets & 10.9 & 20.5 & $88.07 \%$ & $97.70 \%$ & $96.70 \%$ \\
\hline Risk-free assets & 9.8 & 15 & $53.06 \%$ & $97.60 \%$ & $96.50 \%$ \\
\hline Cash & 1.2 & 2 & $66.67 \%$ & $94.10 \%$ & $91.50 \%$ \\
\hline Demand deposits & 10.4 & 15 & $44.23 \%$ & $48.70 \%$ & $56.60 \%$ \\
\hline Time deposits & 41.6 & 50 & $20.19 \%$ & $17.20 \%$ & $18.10 \%$ \\
\hline Balance & 1.5 & 3 & $100.00 \%$ & $66.30 \%$ & $62.00 \%$ \\
\hline Risky assets & 22.9 & 35 & $52.84 \%$ & $18.50 \%$ & $27.80 \%$ \\
\hline Financial products & 104 & 50 & $-51.92 \%$ & $1.70 \%$ & $8.50 \%$ \\
\hline Bank financial product & 104 & 100 & $-3.85 \%$ & $1.70 \%$ & $4.50 \%$ \\
\hline Other financial product & 228.8 & 50 & $-78.15 \%$ & $0.00 \%$ & $0.40 \%$ \\
\hline Internet financial product & NA & 6 & NA & NA & $4.60 \%$ \\
\hline Stocks & 31.2 & 50 & $60.26 \%$ & $5.30 \%$ & $6.50 \%$ \\
\hline Funds & 20.8 & 30 & $44.23 \%$ & $3.10 \%$ & $3.40 \%$ \\
\hline Other risky assets & 15.6 & 40 & $156.41 \%$ & $2.40 \%$ & $1.30 \%$ \\
\hline Loan lent & 20.8 & 20 & $-3.85 \%$ & $11.10 \%$ & $14.40 \%$ \\
\hline Account receivable & NA & 15 & NA & NA & $5 \%$ \\
\hline
\end{tabular}

\subsection{Variables Selection and Model Construction}

\subsubsection{Variables Selection}

The variables in the empirical parts including gender, age, education, marriage, income, risk preference, number of residence, cash gift balance. Actually, these variables can be divided into three groups. The first group named "economic feature of household" including annual income of family and the status of residence. The second group named "domestic nature of household" containing age of household leader, the gender of the leader, the educational background of leader, the marriage of leader and the risk appreciation of the leader. And the final group is social network of the family including cash gift income, cash gift outcome and cash gift balance. Because the concept of social network is abstract here, and the concrete measurement of social network is presented by cash gift income, cash gift outcome and cash gift balance.

After the primary variable selection, some manners should be taken for data. The following is the process of dealing with initial data. The summary of variable selection can be seen in the Table. 
Table 3. Summaries of Selected Variables

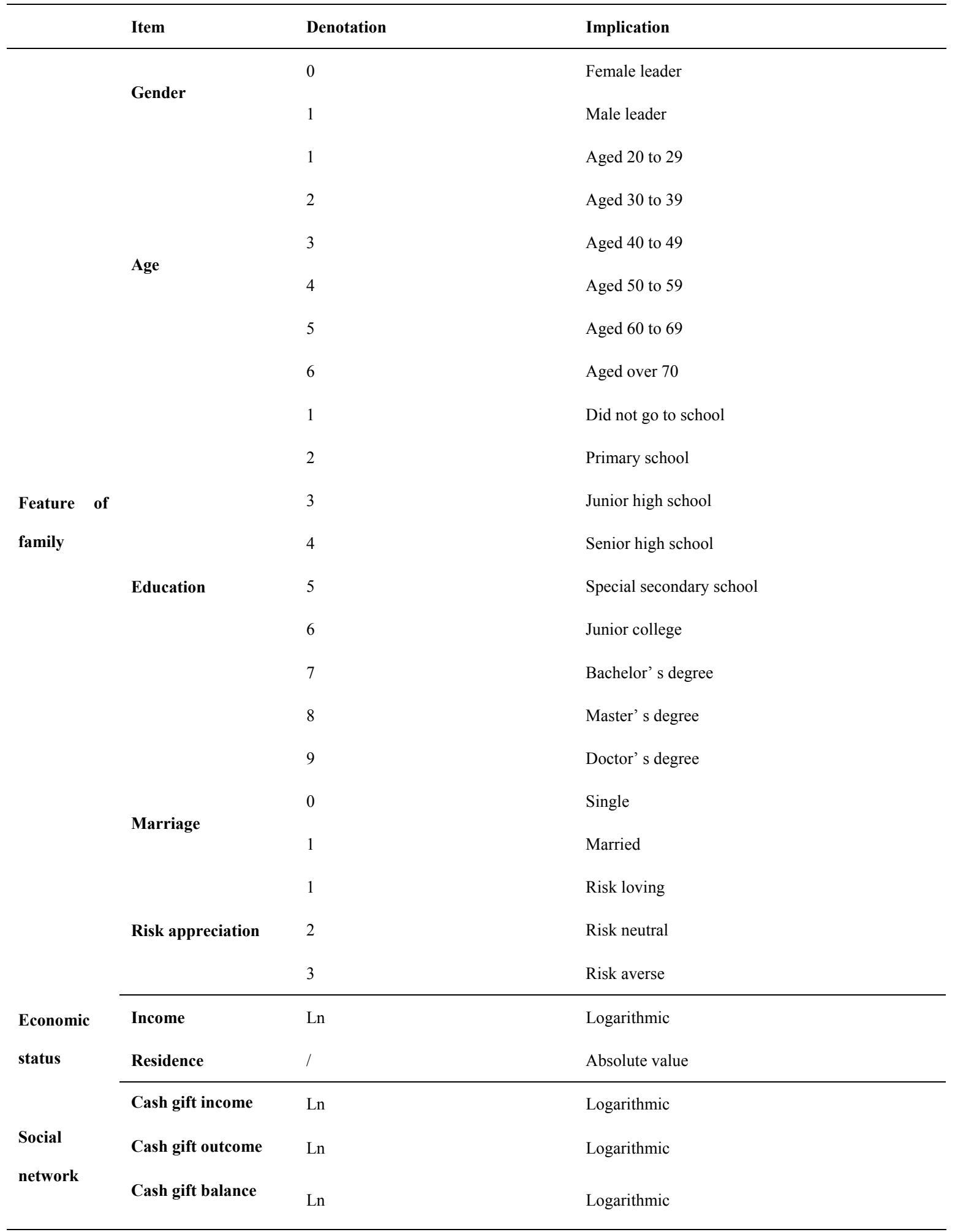

\subsubsection{Design for Model}

The process of financial assets allocation is divided into two phases: the probability of holding stocks is examined in the first phase while the stock-holding as share in aggregate financial assets is tested in the 
second phase. The reason why I only focus on stock instead of other risky financial asset is that stock is an important asset in Chinese household's portfolio taking the first place in risky assets. Household's participation in stock market is a problem of binary probability, and therefore probit model and tobit model are chosen in the particular topic with the concern about the attribute of dependent variable and its independent determinations. Before the explanation of model formulas, basic ideas about probit model and tobit model should be introduced so that I can clarify the reason for adoption of these two types of models.

In terms of study of statistics, probit model is one of regression type in which the dependent variable can only take two values. In essential, the probit model is a type of binary classification model, which is introduced firstly by Chester Bliss in 1934. The probit model treats the same set of problems as logistic regression does with the application of similar techniques. However, the probit model, which employs a probit link function, whose dependent variable follows normal distribution. That is the reason why I employ probit model here instead of logistic model. In the case of the probability that household participate in stock market, the dependent variable is participating in stock market and not participating in stock market. The subjective of the model is to estimate the probability that household with particular characteristics will fall into stock market.

From the scope of tobit model, it is a statistical model which was proposed by James Tobin for the first time in 1958. Therefore, tobit model is named for its innovator Tobin. Fundamentally, the tobit model describes the relationship between a non-negative dependent variable and one or more independent variables. It supposes that there is a latent variable, namely, unobservable variable which linearly depends on hypothesized independent variables through the parameter or the vector which determines the relationship between the independent variables and the latent variable. Additionally, there is a normally distributed error term to capture random influence on the linear relationship. In the specified case of household's financial asset selection, the dependent variables are the weight of stock, the weight of risky assets and the weight of risky assets. These weights are the percentile of particular financial asset in total financial assets.

Generally the great difference lying between probit model and tobit model is the nature of dependent variable. In the probit model, the dependent variable is simply the dummy variable which is denoted as 1 or 0 being dependent on whether the subject household participate in the stock market or not. But in the tobit model, the dependent variable is real variable which can vary from non-negative value. That is the reason why I cannot solely apply probit model or tobit model in the following part even though these two models share similar characteristics and the same independent variables in the explicit function.

Based on the above statistics analysis and associated studies, I construct four dependent variables here. The first dependent variable is the probability that household take part in stock market; the second one is stock as share in total financial assets; the third one is risky assets as share in total financial assets and the last one is the risk-free assets as share in total financial assets. These four dependent variables 
are denoted as stock, stock weight, risky weight and risk-free weight respectively. Fundamentally, stock implies the magnitude of household's participation in stock market. On the other hand, stock weight indicates the depth of household's participation in stock market. If the household invest in stock, then stock is record as 1 , otherwise it is record as 0 . In addition to the specialized study in investors' participation in stock market, the participation in risky asset and risk-free asset are also explored here as few surveyed households take part in stock market. And this phenomenon is common not only in China, but also in other foreign countries. Financial scholars term the abnormal phenomenon "limited participation in stock market”. The following formulas are hypothesized models based on previous analysis and assumption:

Model 1: whether the household participate in stock market or not

$$
\begin{aligned}
& \text { stock }=\gamma_{1}+\gamma_{2} \text { gender }+\gamma_{9} \text { agesquare }+\gamma_{4} \text { education }+\gamma_{6} \text { marriage } \\
& +\gamma_{6} \text { rtsk_averston }+\psi_{4} \text { tricome }+\gamma_{\text {grestalence }} \\
& +\psi_{\text {g soctal_network }}+a
\end{aligned}
$$

Model 2: the depth of household's participation in stock market

$$
\begin{aligned}
& \text { stock wetght }=\gamma_{1}+\gamma_{2} g \text { ender }+\gamma_{\mathrm{a}} \text { agesquare }+\gamma_{4} \text { education }+\gamma_{\mathrm{B}} \text { marrtage } \\
& +\psi_{6} \text { risk_averston }+\psi_{\text {tritame }}+\gamma_{\text {r restdence }} \\
& +\gamma_{\text {g soctal_network }}+\mathrm{a}
\end{aligned}
$$

Model 3: the depth of household's participation in risky assets

$$
\begin{aligned}
\text { risky wetght } & =\gamma_{1}+\gamma_{2} g \text { ender }+\gamma_{\mathrm{a}} \text { age_square }+\gamma_{4} \text { education }+\gamma_{\mathrm{B}} \text { marriage } \\
& +\gamma_{6} \text { rtsk_averston }+\gamma_{8} \text { tricome }+\gamma_{\mathrm{B}} \text { restdence } \\
& +\gamma_{9} \text { soctal_network }+a
\end{aligned}
$$

Model 4: the depth of household's participation in risk-free assets

$$
\begin{aligned}
& \text { rtskfree }=\gamma_{1}+\gamma_{2} g e n d e r+\gamma_{3} a g e_{-} \text {square }+\gamma_{4} \text { education }+\gamma_{8} \text { marriage } \\
& +\gamma_{6} \text { risk_averston }+\psi_{\text {trincome }}+\psi_{0} \text { restdence } \\
& +\chi_{\text {g soctal_network }}+a
\end{aligned}
$$

To test the determinations affecting the household's participation in stock market, probit model is applied to Model 1 because the dependent variable is dummy variable. From the perspective of the depth of household's participation in stock market, risky assets and risk-free assets, tobit model is applied in Model 2, Model 3, and Model 4 for the dependent variables in the above models are real variables.

\subsubsection{Analysis Based on Regression Models}

Both probit model and tobit model are regression models which exploit between the dependent variables and independent variable. They are employed to test the linear relationship between hypothesized determinations and the characteristics of household financial portfolio.

According to the regression outcome in Model 1, household leader's educational background, leader's gender, leader's marriage, annual income of family and the status of residence have significant impact on household's interest in participating in stock market at the confidence level of $10 \%$. In addition, 
family leaders' education level and their gender have positive effect on household's participation in stock market. The reason for that enhancement is that with the progressive education level, the individual investors are more capable to access the magnitude of risk for the household with reasonable understanding in the function in stock market. And these well-educated individual acquire more available information in the market and react more quickly when some changes happen to stock market. The better educated the individual is, the more likely that the household take part in the stock market. If the educational background comes from one level to another higher level, then the possibility of household's involvement in stock market increase by about $2.75 \%$. From the scope of gender, male leader is more possible to invest in stock market. Excepting for the determinations with positive effect, annual income of household, marriage and housing owning exert negative effect on the household's involvement in stock market. At first, the higher income the household earn the lower possibility that the household take part in the stock market. If the income increases $1 \%$, and the probability of stock market involvement decreases $1.34 \%$. Furthermore, married household are less likely to participate in stock market than the unmarried household. Because unmarried household do not have spouse or children, and they are more capable to bear investment risk with more flexibility in fund using so that they can react quickly to unexpected variations in financial market. Finally, household with less residences are more possible to invest in stock market than their counterparts with more residences. This can be understood by the crowding effect between housing investment and stock-holding. Since the household invest in residence which often occupy large amount of financial funds, and consequently, the household have not enough excessive money to invest in stock market. The household add one more residence to their financial portfolio, and then the possibility that the household hold stock decrease around 1.95\%. The last matter should be informed is that the leader's age and risk aversion and the social network of household have not significant impact on household's participation in stock market at the confidence level of $10 \%$.

Model 2 is proposed to analyze the determinations influencing the weight of stock in total financial assets. The weight is treated as an indicator for the depth of household's involvement in stock market and the tobit model is applied to Model 2. The regression result shows that family leader's education level, leader's gender, leader's marriage status, annual income of family and the status exert significant influence on the amount of fund invested in the stock market at the confidence level of $10 \%$. But when it comes into detail, the figure implies that educational background, gender and annual income impact the depth of involvement in stock market positively. In contrast, both marriage status and status of residence have negative impact on the household's activeness in the stock market. The analysis for the different linear relationship among various determinations and household's share-holding comes in the next paragraph.

Model 3 is employed to analyze different determinations of household's investment in risky assets. Similar to the dependent variable in Model 2, the dependent variable in Model 3 is the real value as well, so the tobit model is introduced here to study household's risky asset selection. 
In Model 3, household leader's education level, leader's gender, family's annual income, the condition of marriage and the state of residence play important roles in household's risky asset choice at the confidence level of $10 \%$. The relation between education, gender, and annual income status of residence and household's risky asset selection is positive correlation while the relation between the condition of marriage and household's risky asset selection is negative correlation.

When it comes to a particular variable, the statistics provides evidence that the progression in educational background drives the household more interested in risky asset investment. The increase in an education level contributes the increment of $2.42 \%$ in risky asset as share of total financial asset. Even in the case of risky asset, male investors are more willing to invest money in risky assets. From the standpoint of annual income, the more income the household earn the more money they invest in risky asset market. If the annual income of household increases by $1 \%$ then the share of stock-holding ascends by $1.86 \%$. For the aspect of status of residence, the housing investment does not crowd out risky asset investment according to the statistical illustration of Model 3. Namely, the housing investment does not replace the risky asset in the household's portfolio. Actually in this case, owning residence benefits the risky asset investment even though its contribution is only $0.23 \%$.

On the other hand, the condition of marriage and the activeness in risky asset investment go to opposite direction. Similar to the conclusion based on the findings in last regression model linked to the stock-holding, the household built up by single individual show stronger willingness to hold risky asset compared with married household. Such kind of tendency results from the financial freedom of these unmarried household. When the household transforms from unmarried to married, the share of risky asset goes down by $2.06 \%$.

It is obvious that age, risk aversion and the condition of social network do not have significant impact on the household's risky assets holding at the confidence level of $10 \%$, in particular the age is the most insignificant factor among these tested variables. In other word, the life cycle effect does not exist in the household's risky financial assets in the basis of the statistical result in tobit model 3.

Model 4 is built for analyzing the associated determinations affecting the risk-free asset investment. Since the dependent variable in it is real value, tobit model will be employed to study the characteristics of risk-free asset investment. In the case of holding risk-free asset, only the status of marriage have positive effect on household's risk-free asset selection, which is contrary to the case of risky asset selection. The correlation describes that if the household is married household, then the household will hold more risk-free asset rather than risky asset. Because the married family does not enjoy too much financial flexibility but limited ability to bear risk. So it is quite reasonable that they choose risk-free asset bearing low risk and this choice is commit to their demand for highly liquidity. In the aspect of factors releasing negative effect on risk-free asset investment, the promotional educational background diminishes household's desire for risk-free assets because well-educated household are more capable of handling risk and they prefer financial assets complying with higher return. Moreover, male investors prefer risk-free assets than their female counterparts. For household 
with lower annual income, they are more willing to hold risk-free assets for they are not flexible in financial investment with less available funds. The risk-free asset does not include high risk but high liquidity so the poorer household can use this financial asset to deal with the cash outflow when unexpected accidence happens to them. From the view of condition of residence, the housing investment does not crowd out the risk-free asset investment. The more residence the household have the less risk-free asset they involve into their financial portfolio. In fact, when the household hold one more residence, they will decline $0.73 \%$ of risk-free asset as share in the total financial assets. But even in the case of risk-free asset, the household leader's age, risk aversion and the family's social network are not significant determinations in the examined model at the confidence level of $10 \%$.

Table 4. Statistical Result of Probit Model 1

\begin{tabular}{lcccc}
\hline Variable & Coefficient & Std. Error & z-Statistic & Prob. \\
\hline Age Square & 0.001396 & 0.019312 & 0.072267 & 0.9424 \\
Education & 0.179503 & 0.065366 & 2.746138 & 0.0060 \\
Gender & 1.287578 & 0.622881 & 2.067134 & 0.0387 \\
Income & -0.072150 & 0.053761 & -1.342054 & 0.0496 \\
Marriage & -0.905898 & 0.267714 & -3.383825 & 0.0007 \\
Risk Preference & 0.083600 & 0.079851 & 1.046944 & 0.1751 \\
Residence & -0.387664 & 0.199119 & -1.946891 & 0.0345 \\
Social Network & -0.009295 & 0.028192 & -0.329702 & 0.2525 \\
\hline
\end{tabular}

Table 5. Statistical Result of Tobit Model 2

\begin{tabular}{|c|c|c|c|c|}
\hline Variable & Coefficient & Std. Error & z-Statistic & Prob. \\
\hline Age Square & 0.057754 & 0.061449 & 0.939854 & 0.3473 \\
\hline Education & 0.075960 & 0.038404 & 1.977933 & 0.0479 \\
\hline Gender & 0.894550 & 0.309751 & 2.887961 & 0.0039 \\
\hline Income & 0.150000 & 0.076978 & 1.948610 & 0.0513 \\
\hline Marriage & -0.526479 & 0.160146 & -3.287486 & 0.0010 \\
\hline Risk Preference & 0.029010 & 0.044951 & 0.645372 & 0.5187 \\
\hline Residence & -0.193669 & 0.113213 & -1.710660 & 0.0871 \\
\hline Social Network & -0.094002 & 0.140704 & -0.668082 & 0.2041 \\
\hline
\end{tabular}


Table 6. Statistical Result of Tobit Model 3

\begin{tabular}{lcccc}
\hline Variable & Coefficient & Std. Error & z-Statistic & 0.951148 \\
\hline Age Square & 0.053986 & 0.056759 & 2.423232 & 0.3415 \\
Education & 0.083963 & 0.034649 & 2.046201 & 0.0154 \\
Gender & 0.689236 & 0.336837 & 1.857083 & 0.0407 \\
Income & 0.136382 & 0.073439 & -2.056036 & 0.0633 \\
Marriage & -0.327699 & 0.159384 & 0.760707 & 0.1468 \\
Risk Preference & 0.032739 & 0.043038 & 0.234522 & 0.0146 \\
Residence & 0.021197 & 0.090383 & 0.123782 \\
\hline Social Network & 0.016948 & 0.136920 & 0.2115 \\
\hline
\end{tabular}

Table 7. Statistical Result of Tobit Model 4

\begin{tabular}{|c|c|c|c|c|}
\hline Variable & Coefficient & Std. Error & z-Statistic & Prob. \\
\hline Age Square & -0.026236 & 0.020881 & -1.256466 & 0.2089 \\
\hline Education & -0.024823 & 0.012568 & -1.975001 & 0.0483 \\
\hline Gender & -0.323415 & 0.140448 & -2.302734 & 0.0213 \\
\hline Income & -0.057229 & 0.028495 & -2.008352 & 0.0446 \\
\hline Marriage & 0.135120 & 0.063495 & 2.128038 & 0.0333 \\
\hline Risk Preference & -0.003232 & 0.015968 & -0.202383 & 0.2396 \\
\hline Residence & -0.025329 & 0.034701 & -0.729939 & 0.0654 \\
\hline Social Network & 0.007854 & 0.050298 & 0.156153 & 0.2759 \\
\hline
\end{tabular}

\section{Conclusion}

The China Household Finance Survey suggests that risk-free asset is predominant financial asset in household's portfolio but its importance is weaken by risky asset investment gradually since the awareness of diversification has been strengthen in recent years. It also indicates that the anomalies so called "stock market limited participation" and "Chinese saving puzzle" actually exist within Chinese financial market.

On the one hand, household leader's education background, gender, state of marriage, and household's annual income and residence ownership are significant determinations that influence the probability of participation in the stock market and the depth of the participation. Moreover, leader's age and risk aversion and household's social network cannot impact the household's involvement in the stock market significantly based on the statistics result from probit model and tobit model 2 regressions.

On the other hand, education background, gender, state of marriage, household's annual income and 
condition of housing are significant determinations which influence household's holding risky asset and risk-free asset. But determinations have different extent effect on portfolio construction varying from different categories of financial assets. Generally well-educated household prefer risky assets while less-educated household are inclined to risk-free asset. Besides male investors are more interested in risky asset holding than their female counterparts and the latter tend to choose risk-free asset. From the perspective of state of marriage, unmarried household are more willing to hold risky assets due to their higher financial flexibility. Furthermore, household who earn higher income and own house would like to invest in risky asset, but noticeably, housing investment has crowding effect on investment in risk-free asset. The leader's age, risk aversion and household's social network fail to work on household's portfolio selection significantly again in tobit model 3 and tobit model 4 .

\section{References}

Claus, M., \& Carsten, S. (2010). Dynamic asset allocation with stochastic income and interest rates. Journal of Financial Economics, 16(3), 433-462.

Cocco, J., Gomes, F., \& Maenhout, P. (2005). Consumption and portfolio choice over the life-cycle. Review of Financial Studies, 18(2), 491-533. https://doi.org/10.1093/rfs/hhi017

Huang, Q. (2014). Social network and household portfolio choice. Doctoral Dissertation of Southwestern University of Finance and Economics. Chengdu: Wenjiang.

Li, T. (2006). Social interaction and investment choice. Economic Research Journal, 8, 45-57.

Wei, X. H., Zhang, Y. Y., \& Xiao, S. (2012). The study on factors affect domestic household's financial asset allocations. Economy and Finance, 26, 20-28.

Yin, Z. C., Song, Q. Y., \& Wu, Y. (2014). Financial Knowledge, Investment Experiences and Household Asset Selection. Economic Research Journal, 4, 62-75. 